\title{
CONCEPTS PEOPLE AND POWER IN RUSSIAN AND SPANISH ELECTORAL DISCOURSE
}

\author{
I. Smirnova
}

\author{
Moscow State Institute of International Relations (University) \\ 76, Prospect Vernadskogo, Moscow, 119454, Russia
}

\begin{abstract}
Political communication becomes particularly intense in the pre-election period. Democracy receives criticism aimed to protect the interests of citizens. It is political parties that are responsible for a constructive discussion of their positions and motivating citizens to participate in the election campaign. The electoral language is usually an emotional, connotative language, which resonates with citizens. Political electoral discourse is characterized by certain basic concepts, such as "politics", "election", "electoral programs", "electorate", "people", "power" and others. "People" and "power" are the key ones, since they reflect the features of political process and are inextricably linked to each other during all electoral period. This article focuses on the study of the people / power opposition in the Russian and Spanish electoral discourse and identifies conceptual structures and signs of these concepts.
\end{abstract}

Key Words: people, power, electoral language, political discourse, political party, citizenry, expressional verbal resources, discursive strategy

For citation: Smirnova I.V. (2021). Concepts People and Power in Russian and Spanish Electoral Discourse. Philology at MGIMO, 7(3), pp. 115-120. https://doi.org/10.24833/2410-2423-2021-3-27-115120

\section{CONCEPTOS PUEBLO Y PODER EN EL DISCURSO ELECTORAL RUSO Y ESPAÑOL}

\author{
I. Smirnova \\ Universidad de Relaciones Internacionales de Moscú. \\ 76, avda Vernadskogo, Moscú, Rusia, 119454
}

\begin{abstract}
Resumen: El artículo está dedicado al estudio de la oposición pueblo / poder en el discurso electoral ruso y español. La comunicación política adquiere un carácter especial en el período electoral. La democracia liberal presupone la existencia de una pluralidad de voces críticas que debatan sobre el mejor interés para la ciudadanía. Son los partidos políticos los responsables de incentivar la discusión racional en su modelo de comunicación y, con ello, de motivar en el ciudadano el interés por la participación en una campaña electoral.
\end{abstract}


El lenguaje electoral suele coincidir con el empleo de un lenguaje emotivo, cargado de connotaciones que suelen apelar directamente a los miedos o anhelos de los votantes. Para este tipo de discurso son característicos tales conceptos básicos como "política", "elecciones", "programas electorales", "electorado", "poder", etc. "Pueblo" y "poder" son los conceptos clave porque durante todo el período electoral reflejan las particularidades de este proceso político y están estrechamente relacionados. Precisamente en el discurso electoral se revelan con toda plenitud las estructuras y argumentos conceptuales de estos vocablos.

Palabras clave: pueblo, poder, lenguaje electoral, discurso político, partido político, ciudadanos, recursos expresivos verbales, estrategia discursiva.

Para citación: Smirnova I. (2021). Conceptos Pueblo y Poder en el Discurso Electoral Ruso y Español. Filologia en MGIMO. 7(3), C. 115-120. https://doi.org/10.24833/2410-2423-2021-3-27-115-120

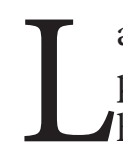

a política engloba diversos factores y elementos que la hacen una de las áreas de estudio más importantes para la sociedad, y puede decirse que el discurso político ha determinado el destino de la humanidad en momentos que hoy se consideran históricos.

El discurso político es una estrategia comunicacional que se sustenta en la creación de un mensaje a través de la conjunción de recursos expresivos verbales, no verbales y paraverbales para persuadir al individuo y a las masas. Es una herramienta esencial para los actores políticos ya que se emplea por éstos para expresar su manera de ver determinados problemas, vincular a los votantes con sus ideales, generar cuestionamientos sobre el ejercicio del poder o crear esperanza en aquellos que reciben el mensaje.

En todas las campañas electorales aparecen diferentes tipos de discursos que tienen como un denominador común persuadir al ciudadano de que sus propuestas son las mejores. Se trata de la propaganda política electoral realizada por los partidos o las fuerzas políticas. La finalidad es conseguir adhesiones a las ideas de diferentes formaciones que se reflejen en un aumento del número de votos.

Los textos, sean orales o escritos, se agrupan en diferentes géneros o tipos de acuerdo a la finalidad y a las características lingüísticas, pragmáticas y retóricas que poseen. Una de esas formas textuales que tiene como finalidad principal la persuasión es la que desarrolla la comunicación política por medio de debates, discursos políticos, programas electorales, eslóganes, etc. [1].

Sin minimizar la importancia que el hecho político tiene de por sí en unas elecciones, hay que reconocer que el lenguaje electoral ocupa en ellas un lugar destacado, tanto más porque son las palabras las que hacen posible la discusión entre candidatos y, puesto que toda batalla política va emparejada a una batalla lingüística, convengamos en que en cualquier período electoral el enfrentamiento lingüístico es intenso.

La comunicación política comprende la actividad de determinadas personas e instituciones en la que se produce un intercambio de información, ideas y actitudes en torno a los asuntos públicos, el discurso político trata de orientar la opinión de los ciudadanos sobre diversas cuestiones públicas y políticas, ofreciendo directrices para la actuación de una persona o entidad en un ámbito determinado [4]. O sea, el discurso politico / electoral es la comunicación entre los políticos y el resto de la sociedad. Esta comunicación ayuda a entender la política, la organización democrática, las relaciones entre el pueblo y el poder, etc.

El poder de las palabras se hace sentir; se discute en torno a una palabra, un sintagma, un eslogan; se polemiza acerca de una "simple frase", lanzada por un partido y refutada, criticada o reformulada por otros... Se da confianza con determinados términos, mientras que con otros se busca producir el efecto contrario. El vocabulario juega, en fin, un papel preponderante dado que es utilizado con vehemencia, elaborando un discurso que se pretende reflejo o reproducción de temas que interesan y preocupan al hombre de la calle, si bien, y ésta es una de las especificidades propias del tiempo electoral que cabe señalar aquí, ese vocabulario es efímero puesto que pierde vigencia después de efectuadas las votaciones [5]. 
La situación electoral es, pues, un contexto lingüístico al que nosotros nos acercamos con el propósito de apreciar el funcionamiento de un discurso que, por darse dentro de una estrategia discursiva tan marcada, remite a un modelo de procesos semánticos, retóricos e ideológicos fuertemente condicionados.

Debido a que son documentos cuya misión principal es la de exponer los principios y propósitos que mueven al candidato-organización a presentarse a las elecciones, todos los grupos, sin excepción, emiten programas y manifiestos dirigidos a todos los ciudadanos (otros textos electorales van destinados a parcelas concretas de la población: circulares personales, declaraciones profesionales, etc.), constituyendo de esta manera una muestra homogénea, un género literario particular a la vez solemne y lacónico.

Para provocar, orientar y reforzar determinadas interpretaciones lingüísticas los políticos se sirven de múltiples elementos, utilizados de forma que no coincidan con su uso sistémico. El emisor del mensaje realiza toda una serie de estrategias pragmáticas con el fin de conseguir lo que se propone.

En dichas circunstancias, en el discurso electoral es necesaria una interpretación pragmática a todos los niveles lingüísticos, tanto léxico, como estilístico y gramatical, debido a que en el lenguaje utilizado por los políticos nada es casual. Especialmente si tomamos en consideración el hecho de que rara vez sus intervenciones sean espontáneas. Más bien suelen seguir un guión elaborado de antemano por un grupo de especialistas en relaciones públicas.

A nivel lexico-semántico, los políticos optan por el uso de palabras clave, como las voces cambio, recuperación, democracia, pueblo, poder, etc. En función de las necesidades, pueden causar el efecto poisitivo en los destinatarios del mensaje, principalmente cuando los políticos hablan de sí mismos o del partido al que representan; o provocar una reacción negativa, habitualmente en relación con sus adversarios políticos. En este contexto los conceptos pueblo y poder adquieren su mayor validez e importancia.

La palabra pueblo proviene del término latino populus y permite hacer referencia a tres conceptos distintos: a los habitantes de una cierta región, a la entidad de población de menor tamaño que una ciudad y a la clase baja de una sociedad.

Según la primera definición, el pueblo es el conjunto de los habitantes de una región, nación o país. Estas personas constituyen una comunidad gracias a que comparten una cultura similar.

En cuanto a su segunda acepción, el pueblo es una entidad poblacional que se dedica principalmente a las tareas agrícolas y que vive en zonas rurales.

El tercer significado hace referencia al pueblo llano, una clase social también conocida como la plebe, las masas o el pueblo trabajador. Esta significación social del pueblo se utiliza desde la época romana [2, p. 291].

De acuerdo al momento histórico el término pueblo se usó de diferentes modos; sin embargo algo que es común desde siempre es que se llama así a un conjunto de personas que se mueven con un mismo objetivo de vida o que comparten los límites de un territorio. De este modo, en la actualidad se denomina pueblo al conjunto de personas que integran un Estado, donde no existen privilegios. El pueblo está formado por todos los individuos que a los ojos de la ley están en igualdad de condiciones.

Continuando con lo antes dicho, ser parte del pueblo en un Estado, es un hecho de suma responsabilidad, un derecho que exige a cambio una toma de consciencia absoluta para realizar bien esta función. Y como no todas las personas que forman parte de los individuos con derecho a voto lo ejercen con responsabilidad, es que se ha puesto en vigencia otro concepto, para definir a este sector, la masa.

Entre pueblo y masa existe una gran diferencia. Se dice que el verdadero pueblo está compuesto por ciudadanos que son realmente conscientes de su responsabilidad, de sus deberes y de sus derechos. Consideran que su libertad se limita donde comienzan la libertad y dignidad de los demás y que la desigualdad no debe ser arbitraria, sino la consecuencia de la heterogeneidad humana, pues nuestras capacidades y voluntades son todas diferentes.

Por su parte la masa se encuentra formada por aquellos individuos que no tienen ideales ni sienten responsabilidad alguna con su entorno. Un hombre-masa se le llama a aquel que no se distingue del resto, a quien no le interesa labrarse un porvenir sino tomar aquello que ya le viene empaquetado. No tiene aspiraciones intelectuales ni espirituales y lo único que espera de la vida es que lo guíen, que le den el "producto terminado". Este sector de la sociedad es enemigo declarado de la democracia y de todo tipo de gobierno donde el pueblo se represente a sí mismo, fundamentalmente porque las masas niegan 
la libertad y destruyen la igualdad; espera que todos se conviertan en espejos de los otros, que sientan amor y odio como "debe hacerse" y sobre todo que nunca expresen sentimientos o ideas contrarias a las "normales". La norma es lo que rige a las masas y es la principal enemiga del pueblo, donde todos somos diferentes y podemos aportar algo para engrandecer nuestras sociedades, porque solo en la diversidad existe la posibilidad del éxito y del crecimiento espiritual o intelectual.

En el discurso electoral el concepto pueblo posee las siguientes interpretaciones:

- fuerza política que apoya al gobierno;

- fuerza política que se opone al poder;

- multitud, masa;

- población, sociedad civil.

Durante las elecciones las fuerzas políticas consideran el pueblo como electorado y tratan de atraerlo a sus filas y hacerlo votar a su favor, por eso el concepto pueblo se emplea como categoría positiva y se refiere a:

- conjunto de personas que integran al Estado o habitantes de una cierta región;

- $\quad$ sociedad civil;

- nación, nacionalidad, minoría étnica;

- pueblo trabajador;

- país.

Entre los denominadores que se emplean en el contexto con el concepto pueblo en el discurso electoral ruso figuran: gente, Rusia, Patria, tradiciones, generaciones, unión fraternal, defensa, idioma ruso, ciudadanos, habitantes, colaboración, hazañas, esencia del Estado, sentido de orgullo, valentía, unidad, historia, patrimonio nacional, etc. [3, p. 20].

En el discurso electoral español el concepto pueblo se emplea como: España, Patria, ciudadanos, cultura nacional, libertad, orgullo, etc. [8], [9].

Junto con la característica del pueblo como sociedad civil se emplean tales denominadores como modernización, energía creativa, realización, instituciones públicas, ciudadanos, movimiento público, relación con el presidente y otros (discurso electoral ruso), innovación, progreso, ciudadanos, futuro, etc.(discurso electoral español).

Se puede decir, que en general el discurso político y electoral de Rusia y de España está orientado a los valores nacionales comunes: patriotismo, igualdad de derechos, unidad, conservación de las tradiciones culturales. El pueblo se comprende como una totalidad orgánica, como una indivisible voluntad general.

Durante las campañas electorales el concepto pueblo a menudo se utiliza como instrumento de manipulación política.

Así, la oposición liberal irreconciliable de Rusia, cuyo líder es Alexey Navalny, emplea el concepto pueblo en las siguientes acepciones:

- multitud, muchedumbre, masa;

- víctima;

- ciudadanos de a pie, pueblo llano;

- habitantes del país;

- pueblo trabajador;

- sociedad civil.

Como vemos, en la retórica de los liberales rusos el concepto pueblo junto con el significado neutral tiene también el significado negativo.

El término poder tiene múltiples definiciones y usos. En su acepción básica el concepto de poder aparece en la doctrina política ligado siempre a la capacidad de unas personas de imponer determinadas conductas a otras personas, aún contra la voluntad de estas. Esta palabra se utiliza para describir la facultad, habilidad, capacidad o autorización para llevar a cabo una determinada acción. De todas formas, el uso más habitual del término se refiere al control, imperio, dominio, y jurisdicción de que un hombre dispone para concretar algo o imponer un mandato. Así, el poder se relaciona con el gobierno de un país [2, p.141].

En el discurso político en general y el discurso electoral en particular el concepto poder interpreta un papel muy importante. La mentalidad rusa lo identifica con dirección, fuerza, control, Estado, autoridad, ley, competencias, derecho [3]. 
El concepto poder se realiza por el emisor del mensaje mediante las "palabras clave" o "símbolos" que a su vez provocan las asociaciones concretas. Estos símbolos representan las expresiones que reflejan la idea política y se emplean en el discurso electoral con el objetivo de influir en el auditorio y formar la opinión pública política. Por ejemplo: dominio político, dirección estatal, personas que poseen competencias gubernamentales y administrativas, el curso político del país, el diálogo entre el poder y el pueblo [3].

El partido comunista de la Federación Rusa (cuyo líder es Gennady Zuganov) valora negativamente al Gobierno del país y se expresa al respecto en la estilística del conflicto. Se identifica con la URSS, considerando a sí mismo como la única fuerza política con gran experiencia que en realidad sabe cómo gobernar el Estado. Sin embargo no expone ninguna nueva solución constructiva.

El partido liberal-demócrata de Rusia no se contrapone al poder estatal, criticando solo a algunos representantes del Gobierno.

Para el discurso político español el concepto poder, (del latín potere), se refiere a la capacidad, la facultad o habilidad para llevar a cabo determinada acción. La palabra poder se refiere, en su uso más habitual, a la autoridad de que una o varias personas disponen para llevar el mando de alguna tarea o trabajo, concretar algo que deseen o imponer una orden. En la política el poder se reconoció siempre como la potestad rectora y coactiva del Estado.

En la mentalidad española igual que en la mentalidad rusa poder también se identifica con Estado, control, fuerza, ley, derecho, garantía del futuro, seguridad, estabilidad, experiencia, profesionalidad, realismo, tolerancia, flexibilidad, humanitarismo, iglesia [8], [9].

En este contexto vale la pena mencionar el así llamado quinto poder. Bajo dicha denominación se engloba la Iglesia y la religión. Una institución o una doctrina que también tiene la capacidad para influir sobremanera sobre el ser humano. Las cuestiones de la religión y el poder son inseparables para tales países como España donde la Iglesia Católica siempre ha interpretado un papel muy importante durante toda su historia.

El líder del partido político español "Podemos" Pablo Iglesias criticando al Gobierno dice: "Las amas de casa administran seguramente mejor que cualquier ministro que hayamos tenido" [6].

Los vocablos amas de casa por una parte y administrar y ministro por otra pertenecen a diferentes esferas de comunicación, pero en el contexto político electoral se emplean juntos y de esa manera refuerzan y subrayan la crítica del poder existente.

Muchos opositores se crean una imagen de un partido popular, se contraponen al Gobierno y tratan de identificarse con el pueblo para hacer creer al destinatario que necesitan el poder solo para defender los intereses del pueblo. $\mathrm{Y}$ de esa manera se realiza la táctica persuasiva de cautivar a los electores para que voten a favor de su partido.

Uno de los discursos más importantes debido a su uso y las repercusiones que puede llegar a tener es el discurso político / electoral que no va dirigido a una persona en particular, sino a un grupo de personas, una comunidad, una asociación o a cualquier forma de organización social, que puede ejercer o hacer efectivo algún tipo de poder. El espacio social se percibe como un escenario conflictivo con líneas de tensión permanentes y actores en constante pugna: el pueblo y los "poderosos". Se trata de categorías complementarias y contrarias al mismo tiempo.

A veces, al hablar del grupo antagónico que se opone al pueblo, se trata más de ideas que de términos concretos: los poderosos, el poder, los políticos, la gente de dinero, etc. Es un grupo definido en negativo, por su no pertenencia al pueblo, por unas prácticas, unos hábitos de comportamiento y consumo, y unos intereses distintos, e incluso opuestos, a los del pueblo [7].

El breve análisis de los conceptos pueblo y poder nos permite llegar a las siguientes conclusiones:

1. En el discurso político contemporáneo, cuyo objetivo pragmático es el establecimiento y el mantenimiento de las relaciones de la dominancia y la subordinación, el concepto pueblo significa "población", "sociedad civil", "ciudadanos", etc. y representa uno de los conceptos básicos junto con tales como poder, política, estado y otros;

2. Todos los representantes de las fuerzas políticas que pretenden llegar al poder articulan sus discursos a partir del concepto pueblo; hablan en nombre del pueblo, lo que es uno de los mecanismos persuasivos muy eficientes. En ese combate por el poder que son las elecciones, los partidos-candidatos 
construyen un discurso hábilmente dirigido y organizado en vistas a conseguir el fin deseado: el apoyo del ciudadano a la propuesta ideológica que ofrecen. La oposición pueblo / poder ordena casi todos los niveles del discurso político en general y del discurso electoral en particular.

3. Los conceptos pueblo y poder tanto en el discurso electoral ruso como español se emplean juntos como dos componentes de un proceso político y son inseparables durante el período electoral. Ambos conceptos forman parte de un mecanismo que tiene por objetivo persuadir al ciudadano de que las propuestas de un partido o una fuerza política son las más convenientes.

Como vemos, la interpretación y el empleo de los conceptos pueblo y poder en el discurso electoral ruso y español en general coinciden lo que consideramos absolutamente lógico.

(С) Смирнова И.В., 2021

\section{Referencias bibliográficas}

1. Демьянков В.3. Прагматика коммуникации и когниция // Когнитивные исследования языка. Вып. 29. Когниция и коммуникация в лингвистических исследованиях. Тамбов, 2017. С. 17 - 18.

2. Лингвистический энциклопедический словарь. М., 1990. 478 с.

3. Рогачева Т.Н. Концепт «народ» в политическом дискурсе web-пространства. // Современный дискурс-анализ. Белгород, 2018. С. $19-23$.

4. Canel, M.J. Comunicación Política. Técnicas y estrategias para la sociedad de la información. Madrid, 1999. 143 pp.

5. Escandell Vidal, M. Introducción a la pragmática. Barcelona: Ariel, 1996. 256 pp.

6. Iglesias P. Discurso íntegro de Pablo Iglesias en la Puerta del Sol [Электронный pecypc] 04.02.2015. 2015b. URL: https:// www.lamarea.com/2015/02/04/discurso-integro-de-pablo-iglesias-en-la-puerta-del-sol/ (дата обращения 10.07.2019).

7. Mocovic, M. et al. Análisis argumentativo de los debates electorales: la construcción del enemigo. // Revista Latina. Universidad de la Laguna, №76, 2020. P. 189 - 207.

8. Programa electoral 2015 - PSOE. 287 pp.

9. Programa electoral del Partido Popular. 2015. $221 \mathrm{pp}$.

\section{References}

1. Demiankov, V.Z. Pragmatica kommunikatsii i kognitsia [Pragmatics of commuinication and cognitions] // Kognitivnye issledovania iazyka [Cognitive investigations of language]. Issue 29. Kognitsia i kommunikatsia v lingvisticheskikh issledovaniakh [Cognitions and communication in linguistic investigations]. Tambov, 2017. P. 17-18.

2. Lingvisticheskiy entsiklopedicheskyi slovar' [Linguistic encyclopaedical dictionary]. Moscow, 1990. 478 p.

3. Rogacheva, T.N. Contsept "narod" v politicheskom discurse web-prostranstva [Concept "people" in the political discourse of web-space]. // Sovremenni discurs-analis [Modern discourse-analysis]. Belgorod. P.19-23.

4. Canel, M.J. Comunicación Política. Técnicas y estrategias para la sociedad de la información. Madrid, 1999. 143 pp.

5. Escandell Vidal, M. Introducción a la pragmática. Barcelona: Ariel, 1996. 256 pp.

6. Iglesias, P. Discurso íntegro de Pablo Iglesias en la Puerta del Sol [Electronic source] 04.02.2015. 2015b, www.lamarea. com/2015/02/04/discurso-integro-de-pablo-iglesias-en-la-puerta-del-sol/ (Accessed 10.07.2019).

7. Mocovic, M. et al. Análisis argumentativo de los debates electorales: la construcción del enemigo. // Revista Latina №76, Universidad de la Laguna, 2020. - P. 189 - 207.

8. Programa electoral 2015 - PSOE. 287 pp.

9. Programa electoral del Partido Popular. 2015. 221 pp.

\section{Сведения об авторе:}

Смирнова Ирина Владимировна - кандидат филологических наук, доцент кафедры испанского языка, Московский государственный институт международных отношений (университет) МИД России. Сферы научных интересов: лексикология, семантика, лингвопрагматика. E-mail: irina-smirnova1402@yandex.ru

\section{About the author:}

Irina V. Smirnova - PhD (Philology), Associate Professor, Spanish Language Department of Moscow State Institute of International Relations (University). Research interests: lexicology, semantology, lingvopragmatics. E-mail: irina-smirnova1402@yandex.ru 